\title{
International Academy of Health Sciences Informatics (IAHSI): \\ Strategy and Focus Areas, 1st Version*
}

\author{
Fernando Martin-Sanchez ${ }^{1}$, Marion J. Ball ${ }^{2}$, Michio Kimura ${ }^{3}$, Paula Otero ${ }^{4}$, Elaine Huesing ${ }^{5}$, \\ Christoph U. Lehmann ${ }^{6}$, Reinhold Haux ${ }^{7}$ \\ 1 Digital Health Research Department, Instituto de Salud Carlos III, Madrid, Spain \\ 2 Multi-Interprofessional Center for Health Informatics (MICHI), University of Texas at Arlington, TX, USA \\ 3 Medical Informatics Department, School of Medicine, Hamamatsu University, Shizuoka, Japan \\ ${ }^{4}$ Department of Health Informatics, Hospital Italiano de Buenos Aires, Argentina \\ 5 International Medical Informatics Association (IMIA) \\ ${ }^{6}$ Clinical Informatics Center, University of Texas Southwestern Medical Center, Dallas, TX, USA \\ 7 Peter L. Reichertz Institute for Medical Informatics of TU Braunschweig and Hannover Medical \\ School, Germany
}

\section{Summary \\ Background: The International Academy of Health Sciences \\ Informatics (IAHSI) is the Academy of the International Medical Informatics Association (IMIA). As an international forum for peers in biomedical and health informatics, the Academy shall play an important role in exchanging knowledge, providing edu- cation and training, and producing policy documents. \\ Objectives: A major priority of the Academy's activities in its inaugural phase was to define its strategy and focus areas in accordance with its objectives and to prioritize the Academy's work, which can then be transferred to respective taskforces. Method: This document reflects the major outcomes of intensive discussions that occurred during 2019. It was presented at the Academy's 3rd Plenary on August 25th, 2019, in Lyon, France.}

\begin{abstract}
Results: Regardless of the 'living nature' of the strategy and focus areas document, it was concluded during the Plenary that the first version, which will be used as a base for decisions on the Academy's future activities, should be made available to a broad audience. Three out of eight 'Visions for IAHSI', presented in the IMIA Yearbook of Medical Informatics 2018, were identified as central for developing, implementing, and evaluating the Academy's strategic directions: (1) advise governments and organizations on developing health and health sciences through informatics, (2) stimulate progress in biomedical and health informatics research, education, and practice, and (3) share and exchange knowledge. Taskforces shall be implemented to work in the following areas, which were considered as priority themes: (1) artificial intelligence in health: future collaboration of entities
\end{abstract}

with natural and with artificial intelligence in health care, and (2) current landscape of standards for digital health.

Conclusions: Taskforces are now being established. Besides specific key performance indicators, suggested for monitoring the work of theses taskforces, the strategy to monitor the progress of the Academy itself has to be measured by relevant and acceptable metrics.

\section{Keywords}

Biomedical and health informatics; Medical informatics; Health informatics; Academy of Sciences; International Academy of Health Sciences Informatics.

Yearb Med Inform 2020:15-25

http://dx.doi.org/10.1055/s-0040-1701992

The core commitment of academies of sciences, according to The French Académie des Sciences, is twofold: the advancement of science and the advice to government authorities. It is a double calling that has been reinforced over time, as and when our knowledge base itself has progressed.

\footnotetext{
This document was presented at the Academy's 3rd Plenary on August 25, 2019, in Lyon, France. Academy Fellows voted that, regardless of the 'living nature' of the strategy and focus areas document, decisions on future activities will be based on the first version for now. Because of the importance of the document and of its comprehensive content, the decision was made to publish
}

an edited version of the complete document in the 2020 edition of the IMIA Yearbook. In this edited version a summary and keywords have been added. All web-addresses have been checked and, where necessary, updated on March 31, 2020. Some spelling errors were corrected. Provisionally mentioned names for taskforce members have been removed. Academy Board members (elected and ex-officio) during the time period where the strategy and focus areas document had been elaborated are listed as authors. The first author has chaired this activity. The last and corresponding author prepared the edited version. Fellows having contributed to this strategy and focus areas document are listed in the acknowledgements. 


\section{Introduction: What IAHSI Is}

The International Medical Informatics Association (IMIA) is the world peak body for health and biomedical informatics ${ }^{1}$ and an "association of associations". IMIA has recently established the International Academy of Health Sciences Informatics (IAHSI) and completed the election process of leaders in this field worldwide, who have become the first class of Fellows of the Academy. The Academy will serve as an honor society that recognizes expertise in biomedical and health informatics internationally. The Academy exists as an elected body of members incorporated within IMIA.

IAHSI is the learned society of IMIA. A learned society, also known as a learned academy, scholarly society, or academic association, is an organization that aims to promote a profession, academic discipline (Biomedical and Health Informatics), or a group of related disciplines (Health Sciences Informatics). In particular, academies have long played a key role in providing academic expertise to government and international organizations for their decision-making.

IAHSI is a learned society of experts across the world in the discipline of biomedical and health informatics. Some of the members of the Academy are founders of this discipline and other members are knowledge experts of this discipline today. Their expertise can be of remarkable assistance to benefit the world's people.

IAHSI acknowledges the interdisciplinary nature of health sciences informatics, and promotes a multi-professional field, - as a community of diverse and complementing contributions among all experts in the application of informatics to the health sciences.

A definition for Biomedical and Health Informatics (HBI) can be found at: https:// www.amia.org/sites/default/files/What-isInformatics-Fact-Sheet-040811.pdf. We utilize this term inclusively, encompassing areas such as e-Health, Digital Health, Health Information Technology (IT), or the different HBI subspecialties (e.g., clinical informatics, nursing informatics, public health informatics, translational bioinformatics).
IAHSI must be very aware that it is part of a broader advisory ecosystem, with many other stakeholders, where becoming relevant poses some challenges. At the same time, academies, by their very nature, are generally conservative institutions comprising "elite experts". This poses some risks (marginalization, irrelevance) particularly in our field, which is a very dynamic one.

Fellows of the Academy, as prerequisite and ongoing requirements for membership, shall bind to internationally accepted codes of ethics and professional conduct, including the IMIA one, in all actions among the Academy, between the Academy and IMIA, and the Academy and its stakeholders and clients.

In order to avoid any internal competition, the Academy vision and strategies shall clearly avoid any "parallel structures and functions" with its parent organization (IMIA). If any restructuring or redefining of the IMIA missions and activities was needed, the Academy shall prepare proposals to IMIA Board and General Assembly for approval or vice versa.

IAHSI must be cost neutral to its parent organization (IMIA) so it needs a sustainable source of funds in order to support its mission, strategic directions, and activities. The IAHSI fellowship fees may just cover administrative and meeting costs but are definitely insufficient. The Academy needs to develop different mechanisms for fundraising including, for instance:

- Consistent marketing and sustainable visibility to promote world-class consultancy services to governments and organizations.

- Fundraising including but not limited to "national level grant applications", "regional level fund applications", "international joint initiatives proposals". The Academy could appoint a dedicated team of fellows who are experts in developing and submitting such applications.

- Organizing joint events including seminars, workshops, discussion panels, webinars, and conferences with similar organizations.
This document provides guidelines for IAHSI's strategic direction, identifying focus areas, priorities, and a short-term action plan.

\section{IAHSI Vision, Mission, Principles, and Values}

\section{Mission}

The Academy stimulates progress in biomedical and health informatics research, education and practice, advices governments and organizations on developing health and health sciences through informatics, and shares and exchanges knowledge among members and stakeholders.

\section{Principles of the Academy Activities}

- The Academy's structure and organization should follow the tradition of scientific societies

- The Academy's structure and organization should be lean and unbiased

- The Academy should meet where IMIA meets

\section{Core Values}

- Commitment to science always seeking the best evidence

- Sharing knowledge

- Transparency

- Constructive collaboration

- Ethical professional practice

- Entrepreneurial mindsets

- Innovation

- Inclusiveness

- Passion

- Respect 


\section{Stakeholders and Networks}

- IMIA Members, Working Groups (WGs), and Special Interest Groups (SIGs)

- International and global science organizations

- International Health Professional Associations (ICN, WONCA, WMA, IAHCP, CSDS, etc.)

- International health-related organizations (WHO, IHF, ISFTeH etc.)

- National Academies (or regional, like FEAM - Fédération Européenne des Académies de Médecine, Bruxelles).

- Standards development organizations (ISO, GS1, HL7, CEN, ITU, openEHR, etc.)

- Patient associations

- Public and private insurances, philanthropic, as well as industry associations

- Political networks, trade delegations, Asia-Pacific Economic Cooperation (APEC), etc.
- Clinical Trial and other global research institutions

- Big data companies

\section{Strategic Directions for IAHSI}

The discipline of biomedical and health informatics can have a positive impact on the health of the world's population. Health and health care is an information business, and the quality, efficiency, effectiveness, and outcomes of care depend on the informatics and Health IT "tools of the trade" to put the right information on the right person into the right hands at the right time and in the right way to allow the best decisions to be made to support health of the world and health care of individual persons and populations. Of particular concern to the Academy are health care data, information, knowledge, and wisdom, communicated through appropriate channels. The world-wide leaders elected to IAHSI have the knowledge to help governments and organizations improve the health of the world. IAHSI should be a global expectation-setting body for biomedical and health informatics.

Based on the article published by Haux, R. "Visions for IAHSI" [Haux, 2018], the eight visions have been reorganized in three areas, as represented in Figure 1. There is an overarching goal, which corresponds to the Vision (V) of the Academy. At the base, there are four supporting activities (SA5-SA8), since they help to articulate the structure of the organization and to develop its activity. The central part is the one on which this document focuses since it represents the strategic directions (SD2-SD4) of IAHSI activity that are to be developed, implemented, and evaluated to accomplish its mission.

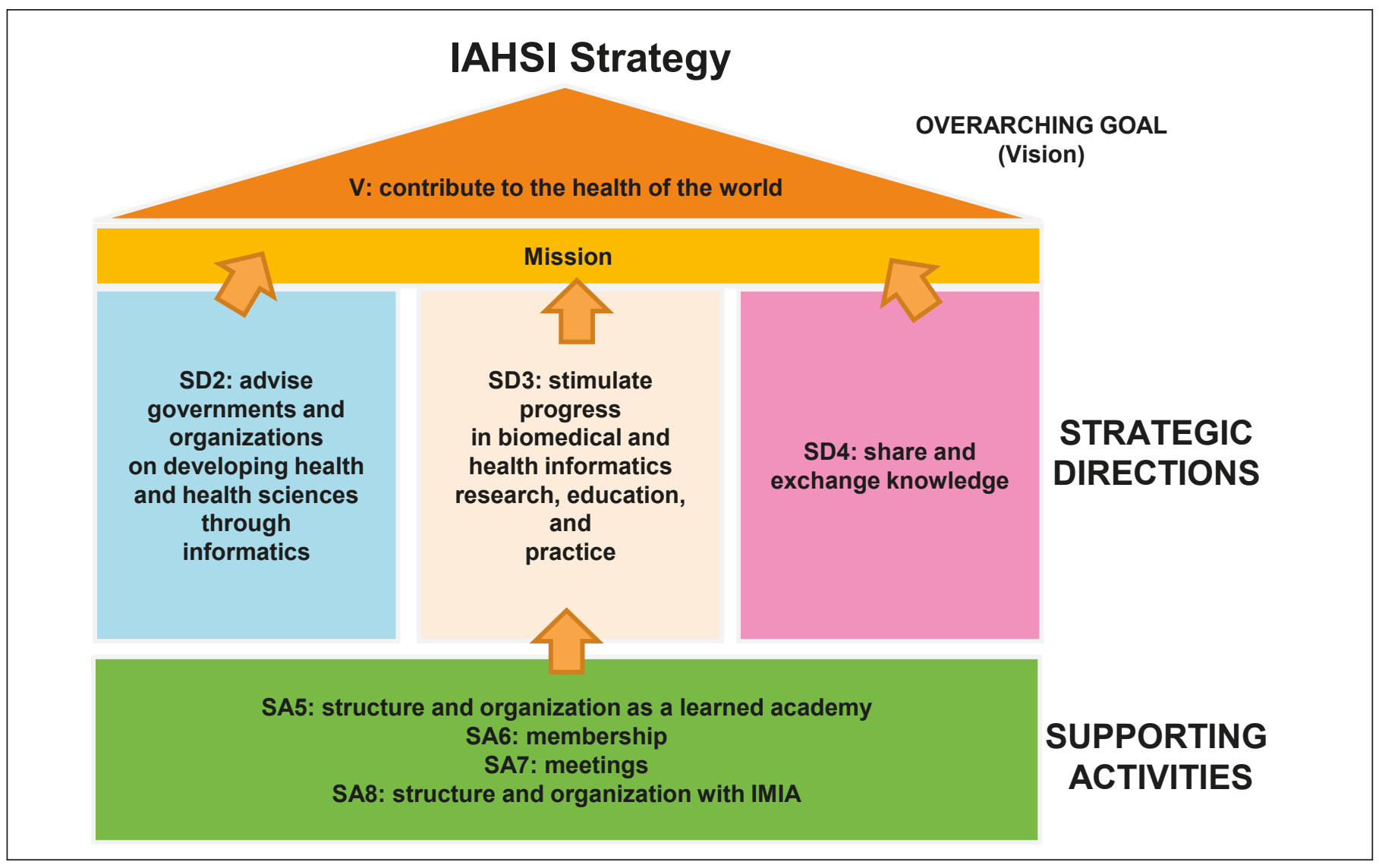




\section{V: Contribute to the Health of the World}

IAHSI should contribute to the health of the world [Crist, 2018].

The 2030 Agenda for Sustainable Development, adopted by all United Nations Member States in 2015, provides a shared blueprint for peace and prosperity for people and the planet, now and into the future. At its heart are the 17 Sustainable Development Goals (SDGs), which are an urgent call for action by all countries - developed and developing - in a global partnership. They recognize that ending poverty and other deprivations must go hand-in-hand with strategies that improve health and education, reduce inequality, and spur economic growth - all while tackling climate change and working to preserve our oceans and forests.

"Good health is one of humanity's most valued assets. It is key to advancing sustainable development - to end poverty, promote peaceful and inclusive societies and protect the environment". IAHSI commits with the SDG health goal (SDG 3), as stated in the Global Action Plan for Healthy Lives and Well-being for all, ${ }^{2}$ and with Universal Health Coverage in particular.

To ensure clinical relevance, the Academy needs to have both regional and professional impact. With that purpose, it will liaise with IMIA regional chapters and other regional entities as well as with professional societies to make sure that the health professionals' voice is heard well. IAHSI will also seek to collaborate with patient associations.

Biomedical and Health Informatics is a key scientific component underpinning current trends in biomedical research, health care, and population health (e.g., data science, digital health, artificial intelligence, precision health). Developments in these new areas need to be evidence-informed and evaluated in terms of clinical significance today and in the future. The Academy should be prepared to provide leadership in Biomedical and Health Informatics. For example, one of the serious issues that is frequently overlooked is that standards are being developed (e.g., ISO T4, SNOMED) and there is little international uptake. The Academy should be providing leadership in our own countries and internationally in promoting the adoption and use of such international standards.
The Academy should also contribute to upgrading the health professional's voice - to make sure our contributions are clinically relevant - not just technological opportunities. Active inclusion of professionals and establishing strong and lasting collaborative agreements with health and clinical professional bodies seems important - (for instance, when we see how Electronic Health Record systems (EHRs) quite often add burden to the clinician).

Of particular interest is how IAHSI can contribute to strengthen IMIA relationship with WHO. WHO has recently announced important changes in its structure, creating a Division on Digital Health and a new Unit for Artificial Intelligence ${ }^{3}$ as well as Recommendation Guidelines for Digital Interventions ${ }^{4}$. IAHSI may be able to use its membership to (1) identify current matters where a WHO leadership is likely to have positive outcomes, and (2) derive some principles for WHO action in this arena by surveying past good and bad experiences always leading with the positive.

The Academy should achieve this by:

\begin{tabular}{|c|l|l|l|}
\hline Vision & \multicolumn{1}{|c|}{ Objective } & Activities & Priority \\
\hline $\mathrm{V}$ & $\begin{array}{l}\text { V.O1 Developing further the IMIA } \\
\text { liaison with WHO, taking into account } \\
\text { the recent WHO activities in Digital } \\
\text { Health (guidelines, consultation, new } \\
\text { structure) }\end{array}$ & $\begin{array}{l}\text { V.O1.A1 Present IAHSI to WHO } \\
\text { officials along with the capabilities of its } \\
\text { members to make a difference }\end{array}$ & High \\
\hline $\mathrm{V}$ & $\begin{array}{l}\text { V.O2 Putting in place mechanisms to } \\
\text { make sure IAHSI is listening to the } \\
\text { patients' voice }\end{array}$ & $\begin{array}{l}\text { V.O2.A1 Liaise with inclusive scientific } \\
\text { societies (e.g., Society for Participatory } \\
\text { Medicine) }\end{array}$ & High \\
\cline { 3 - 5 } & $\begin{array}{l}\text { V.O3 Becoming relevant to the public, } \\
\text { Vo IAHSI becomes relevant to } \\
\text { Vovernments }\end{array}$ & $\begin{array}{l}\text { V.O3.A1 Design and develop a } \\
\text { dissemination policy }\end{array}$ & Medium \\
\cline { 3 - 5 } & $\begin{array}{l}\text { V.O3.A2 Create a one-page statement on } \\
\text { why Health Sciences Informatics is } \\
\text { critical to improving people's health }\end{array}$ & High \\
\hline $\mathrm{V}$ & $\begin{array}{l}\text { V.O4 Providing leadership in } \\
\text { Biomedical and Health Informatics }\end{array}$ & $\begin{array}{l}\text { V.O4.A1 Promote the adoption and use } \\
\text { of international HBI standards }\end{array}$ & High \\
\hline $\mathrm{V}$ & $\begin{array}{l}\text { V.O5 Upgrading the health } \\
\text { professional's voice }\end{array}$ & $\begin{array}{l}\text { V.O5.A1 Establish collaborative } \\
\text { agreements with health and clinical } \\
\text { professional bodies }\end{array}$ & Medium \\
\end{tabular}
03-2019-who-unveils-sweeping-reformsin-drive-towards-triple-billion-targets

4 https://apps.who.int/iris/bitstream/handle/10 665/311941/9789241550505-eng.pdf?ua $=1$ 
SD2: Advise governments and organizations on developing health and health sciences through informatics

The Academy should serve governments and (primarily international) organizations by providing information and by advising on informatics' contributions to health and wellbeing. Academy Fellows have significant experience and standing in the scientific, policy, engineering, operational, and commercial facets of health sciences informatics. That experience should contribute to the holistic nature of any statements/output made by IAHSI which should be wider than the Academic sector. IAHSI Fellows are sufficiently professional to be able to input / comment without introducing bias through 'vested political and commercial interests'. There could be opportunities for funding from non-academic sources for advice/assessments from consultancy and experience-based guidance (for example EU research sources or international think tanks).
The Academy needs to focus on its core competencies in the academic sector and to respect the importance and the roles of other stakeholders in governments and industries. The most important target of IAHSI's dissemination activities might be the upper echelons - the governments, large organizations, big companies - the ones who create facts that our field has then to account for without having been asked for advice, let alone been listened to.

Academies are institutions that have the credibility to inform the public and policy makers about problems and their potential solutions. This credibility comes not only from the scientific excellence of their members but also from their freedom from vested political and commercial interests.

IAHSI should speak with one clear voice for Health Sciences Informatics, applying rigorous standards of scientific criticism in a constructive manner and contributing to assuring evidence-informed public policy.

IAHSI formally recognizes the needs to produce and share artifacts/reflections /evidence /expertise via the web and other online channels on a more 'open' basis, wherever possible.

It is also critical that IAHSI maintains social responsibility for all its scientific activities, following these guidelines when interacting with governments and organizations: - Transparency rather than confidentiality; - Long-term preferred to short-term (Parliament vs Government).

Although advice is, in principle, preferred to advocacy, we must recognize that when an organization is new and has yet to find its grounds (only within IMIA we are well established), advocacy will be a need. Moreover, health sciences informatics itself is not so well established - at least within some major stakeholders / regions. So hereto, advocacy is a current need for the short term. IAHSI's advice should pursue relevance, timeliness, and receptivity, focusing on problems that need solving rather than providing solutions in search of problems.

The Academy should achieve this by:

\begin{tabular}{|c|c|c|c|}
\hline SD & Objective & Activities & Priority \\
\hline SD2 & $\begin{array}{l}\text { SD2.O1 Identifying areas of specialization } \\
\text { and experts }\end{array}$ & $\begin{array}{l}\text { SD2.O1.A1 Proactively establish a } \\
\text { network of scientific advisors } \\
\text { specialized in focused areas (public } \\
\text { health, clinical research, data } \\
\text { science, AI), based on IMIA } \\
\text { Scientific Map }\end{array}$ & High \\
\hline SD2 & $\begin{array}{l}\text { SD2.O2 Elaborating recommendations and } \\
\text { synthesizing the results of the position } \\
\text { papers to demonstrate their importance to } \\
\text { the health of the world }\end{array}$ & $\begin{array}{l}\text { SD2.O2.A1 Produce position papers } \\
\text { and consensus studies, providing a } \\
\text { multi-perspective, evidence-based } \\
\text { view on a particular topic (with panel } \\
\text { of experts, not necessarily Academy } \\
\text { Fellows) }\end{array}$ & High \\
\hline \multirow[t]{2}{*}{ SD2 } & \multirow[t]{2}{*}{ SD2.O3 Distributing best evidence } & $\begin{array}{l}\text { SD2.O3.A1 Generate selection of } \\
\text { reference papers and make them } \\
\text { available on the web }\end{array}$ & High \\
\hline & & $\begin{array}{l}\text { SD2.O3.A2 Select and provide links } \\
\text { to reference Biomedical and Health } \\
\text { Informatics evaluation } \\
\text { methodologies and frameworks }\end{array}$ & Medium \\
\hline SD2 & $\begin{array}{l}\text { SD2.O4 Reporting on important } \\
\text { international developments in the field }\end{array}$ & $\begin{array}{l}\text { SD2.O4.A1 Produce content to be } \\
\text { distributed by e-newsletter and web } \\
\text { site }\end{array}$ & Medium \\
\hline SD2 & SD2.O5 Suggesting research priorities & $\begin{array}{l}\text { SD2.O5.A1 Prepare strategic } \\
\text { foresighting and prospective studies }\end{array}$ & Medium \\
\hline
\end{tabular}


Some examples of topics for reports:

\begin{tabular}{|c|c|c|}
\hline Position papers & Consensus studies & Foresight (trends) \\
\hline (Statements) & (Respond to controversial issues) & (Anticipate issues) \\
\hline $\begin{array}{l}\text { - Precision medicine } \\
\text { informatics } \\
\text { - What is Biomedical and } \\
\text { Health Informatics - } \\
\text { Where it may be useful }\end{array}$ & $\begin{array}{l}\text { - Future collaboration of entities with } \\
\text { natural and with artificial intelligence in } \\
\text { health care (strongly supported by } \\
\text { Fellows) } \\
\text { - Current landscape of standards for digital } \\
\text { health (gaps, consolidated initiatives, and } \\
\text { roadmap) (strongly supported by } \\
\text { Fellows) }\end{array}$ & $\begin{array}{l}\text { - Integration of phenome, } \\
\text { genome, and exposome data } \\
\text { for future healthcare } \\
\text { - Digital avatars and the next } \\
\text { generation of EHRs } \\
\text { - Digital diagnostics and } \\
\text { therapeutics }\end{array}$ \\
\hline
\end{tabular}

\section{SD3: Stimulate progress in} Biomedical and Health Informatics research, education, and practice

The advice provided by IAHSI can only be valuable if it is based on solid facts and evidence. Therefore, to support the advisory role mentioned in SD2, the Academy must contribute to advancing research in our field. The discipline is expanding based on the magnitude of the data available that can be converted to knowledge and the technologies to rapidly distribute the knowledge.

We need to reach out to create methods of training and understanding of Biomedical and Health Informatics. IAHSI outreach should also recognize the need to build on what exists, at a base level that encompasses the non-academic sphere of biomedical and health informatics and general interested citizens.

It has been suggested that a revision of medical and other health professions education curricula is needed in order to ensure that clinicians acquire basic competence in biomedical and health informatics (for instance, appreciating the value (and limitations) of a standard record structure or the use of health information standards in terminology to maximize the use of artificial intelligence and facilitate secondary use of clinical data) [France, 2018].

The Academy should achieve this by:

\begin{tabular}{|c|c|c|c|}
\hline SD & Objective & Activities & Priority \\
\hline SD3 & $\begin{array}{l}\text { SD3.O1 Contributing to advancing } \\
\text { research, education, and practice in our } \\
\text { field }\end{array}$ & $\begin{array}{l}\text { SD3.O1.A1 Create committees of } \\
\text { Academy Fellows and produce } \\
\text { evidence on certain relevant } \\
\text { informatics topics and presenting or } \\
\text { publishing their deliverables. }\end{array}$ & Medium \\
\hline SD3 & $\begin{array}{l}\text { SD3.O2 Recognizing and honoring } \\
\text { excellence }\end{array}$ & $\begin{array}{l}\text { SD3.O2.A1 Establish Academy } \\
\text { awards (medals, lectureships, etc.) to } \\
\text { outstanding informatics research or } \\
\text { education or practice of excellence } \\
\text { with global impact. }\end{array}$ & Medium \\
\hline \multirow[t]{2}{*}{ SD3 } & \multirow[t]{2}{*}{$\begin{array}{l}\text { SD3.O3 Identifying and nurturing scientific } \\
\text { talent }\end{array}$} & $\begin{array}{l}\text { SD3.O3.A1 Award scholarships and } \\
\text { fellowships amongst the young. }\end{array}$ & High \\
\hline & & $\begin{array}{l}\text { SD3.O3.A2 Identify and offer } \\
\text { mentorship of young / potential HSI } \\
\text { young people by utilizing the } \\
\text { knowledge base and domain } \\
\text { experiences of existing IAHSI } \\
\text { Fellows }\end{array}$ & Medium \\
\hline SD3 & $\begin{array}{l}\text { SD3.O4 Promoting excellent research and } \\
\text { disseminate knowledge to the community }\end{array}$ & $\begin{array}{l}\text { SD3.O4.A1 Organize meetings, } \\
\text { events }\end{array}$ & High \\
\hline
\end{tabular}




\section{SD4: Share and exchange knowledge} Academy members should share and exchange their knowledge on important developments in health sciences informatics. This should be achieved through both physical and virtual meetings. Topics for discussion should be of international relevance and originality with the potential to have an impact on the vision (V) and SD2-3.

The Academy can and must avoid practices and attitudes that maintain the image of an "elitist club of experts", so activities will aim at increasing equality of access and dissemination as far as possible.

Fellows need to experiment with different roles and models of engagement. This will require new skills for making better use of dig- ital communication channels and social media platforms. A unified voice for the Academy can have a great impact at the international level, as it is feasible to produce multilingual materials. At the same time, ensuring cultural, gender, economic, and regional diversity will help us to identify and challenge any hidden biases in our activities and products.

In accordance with the draft WHO Global Strategy for Digital Heath proposal, ${ }^{5}$ we, at IMIA, and especially at IAHSI, should start a discussion around a Digital Health Global Agenda to promote all the benefits of Digital Health and at the same time face up to the growing concerns of misuse of information, fake and deep news, discredit of science, anti-vaxxers and the like. We are in a unique position to help disseminate best-practice and fight all forms of health illiteracy (digital in particular).

The Academy should have appropriate communication guidelines for their Fellows when they make expert pronouncements. For instance, it should always be made clear whether a Fellow is speaking from a personal perspective or as a spokesperson of the Academy or for a specific institution or corporate body.

The Academy should look at using the IMIA Yearbook to publish many of the proposed initiatives - position papers, studies, reference papers, etc. - with IAHSI branding.

The Academy should achieve this by:

\begin{tabular}{|c|c|c|c|}
\hline SD & Objective & Activities & Priority \\
\hline SD4 & SD4.O1 Facilitating knowledge sharing & $\begin{array}{l}\text { SD4.01.A1 Create a virtual } \\
\text { community amongst Fellows }\end{array}$ & High \\
\hline SD4 & $\begin{array}{l}\text { SD4.O2 Joining international and global } \\
\text { science organizations, including: }\end{array}$ & $\begin{array}{l}\text { SD4.O2.A1 } \\
\text { International Science Council (Paris, } \\
\text { France) https://council.science/ } \\
\text { International Network for } \\
\text { Government Science Advice } \\
\text { (INGSA) https://www.ingsa.org/ } \\
\text { InterAcademy Partnership - IAP, } \\
\text { http://www.interacademies.org/ } \\
\text { (Trieste-Italy, Washington DC-US) } \\
\text { The World Academy of Sciences - } \\
\text { (Trieste, Italy) TWAS for the } \\
\text { advancement of science in developing } \\
\text { countries. Legally, TWAS is a unit } \\
\text { within UNESCO. https://twas.org/ }\end{array}$ & Medium \\
\hline \multirow[t]{2}{*}{ SD4 } & \multirow[t]{2}{*}{$\begin{array}{l}\text { SD4.O3 Making appropriate expert } \\
\text { pronouncements }\end{array}$} & $\begin{array}{l}\text { SD4.O3.A1 Develop communication } \\
\text { guidelines for Fellows }\end{array}$ & High \\
\hline & & $\begin{array}{l}\text { SD4.O3.A2 Develop a social media } \\
\text { and digital communication policy for } \\
\text { Fellows }\end{array}$ & High \\
\hline
\end{tabular}

5 https://www.who.int/health-topics/digital-health\#tab=tab_1 


\section{Implementation of the IAHSI Strategy}

IAHSI values the science of implementation and evaluation as a critical component of the strategy. The Academy strategy needs to address how the impact of the Academy can be measured by relevant and internationally acceptable metrics. We need to translate the knowledge we generate into practice to achieve overarching goal $\mathrm{V}$ and be relevant.

The Academy will have a demonstration taskforce for strategies SD2, SD3, and SD4. The strategy will be followed or "piloted" for the next year plus and then revisited to see if the Academy is on the correct path or if we need to add objectives or change the priority level for the initial objectives.
Based on the initial proposal and the feedback received, some changes and adjustments have been made and the following three tables summarize the list of activities with their proposed priorities.

The Academy Board will initially appoint one demonstration taskforce for strategies (SD2, SD3 and SD4) and will request expressions of interest from Fellows to join two additional taskforces that will work in the first two scientific publications from IAHSI:

- Future collaboration of entities with natural and with artificial intelligence in health care.

- Current landscape of Standards for Digital Health. There is a lot of confusion in the field of health information standards, but more importantly - there's frustration after so many huge investments in stan- dards implementation that didn't lead to the promised semantic interoperability. The Academy can take the initiative for creating a digital health interoperability framework for the global digital health arena. We need to create a technical framework to analyze the current available standards and clearly identify the interoperability gaps, especially for evaluating and integrating the recent/future digital health interfaces and activity trackers along the electronic health records. Also, this initiative will enable us to take an informative decision whether new digital health interoperability standards will be needed in the near future or not. This could also facilitate making recommendations for adoption of mature standards as there is still a big step to make from an accepted standard to its widespread adoption.

\begin{tabular}{|c|c|c|c|c|}
\hline $\begin{array}{c}\text { Vision / Strategic } \\
\text { Direction }\end{array}$ & Objective & Activity & HIGH PRIORITY & $\begin{array}{c}\text { MEDIUM } \\
\text { PRIORITY }\end{array}$ \\
\hline \multirow[t]{7}{*}{$\mathbf{V}$} & $\mathrm{O} 1$ & A1 & $\mathrm{X}$ & \\
\hline & $\mathrm{O} 2$ & A1 & $\mathrm{X}$ & \\
\hline & & A2 & & X \\
\hline & $\mathrm{O} 3$ & $\mathrm{~A} 1$ & & $\mathrm{X}$ \\
\hline & & A2 & $\mathrm{X}$ & \\
\hline & $\mathrm{O} 4$ & $\mathrm{~A} 1$ & $X$ & \\
\hline & O5 & A1 & & $\mathrm{X}$ \\
\hline \multirow[t]{6}{*}{ SD2 } & $\mathrm{O} 1$ & $\mathrm{~A} 1$ & $\mathrm{X}$ & \\
\hline & $\mathrm{O} 2$ & $\mathrm{~A} 1$ & $X$ & \\
\hline & $\mathrm{O} 3$ & A1 & $\mathrm{X}$ & \\
\hline & & A2 & & $\mathrm{X}$ \\
\hline & $\mathrm{O} 4$ & A1 & & $X$ \\
\hline & O5 & $\mathrm{A} 1$ & & $\mathrm{X}$ \\
\hline \multirow[t]{5}{*}{ SD3 } & $\mathrm{O} 1$ & A1 & $\mathrm{X}$ & \\
\hline & $\mathrm{O} 2$ & $\mathrm{~A} 1$ & $\mathrm{X}$ & \\
\hline & $\mathrm{O} 3$ & A1 & $\mathrm{X}$ & \\
\hline & & A2 & & $X$ \\
\hline & $\mathrm{O} 4$ & A1 & $\mathrm{X}$ & \\
\hline \multirow[t]{4}{*}{ SD4 } & $\mathrm{O} 1$ & $\mathrm{~A} 1$ & $\mathrm{X}$ & \\
\hline & $\mathrm{O} 2$ & A1 & & $\mathrm{X}$ \\
\hline & $\mathrm{O} 3$ & A1 & $X$ & \\
\hline & & $\mathrm{A} 2$ & $X$ & \\
\hline TOTAL & & 22 & 14 & 8 \\
\hline
\end{tabular}




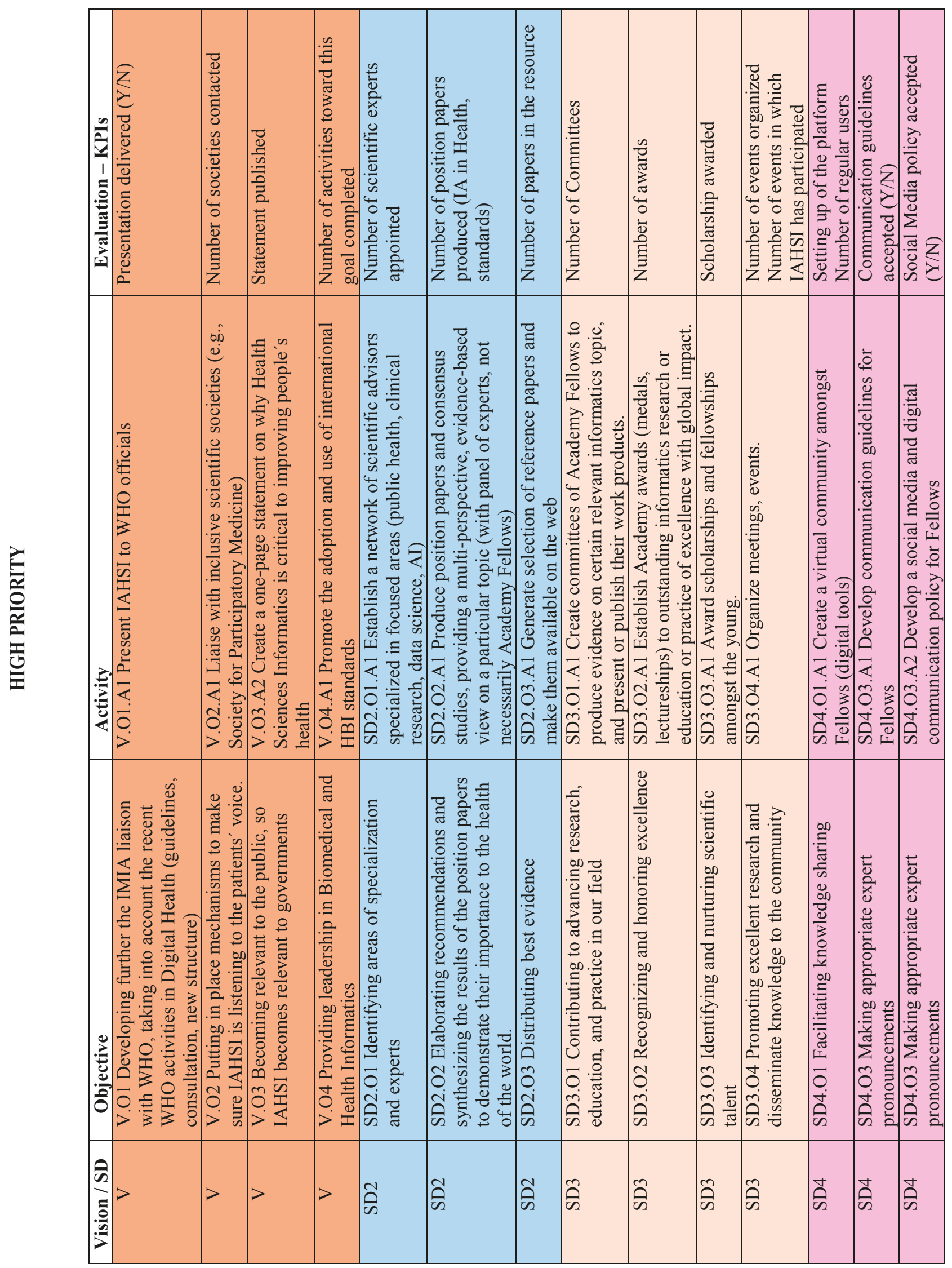




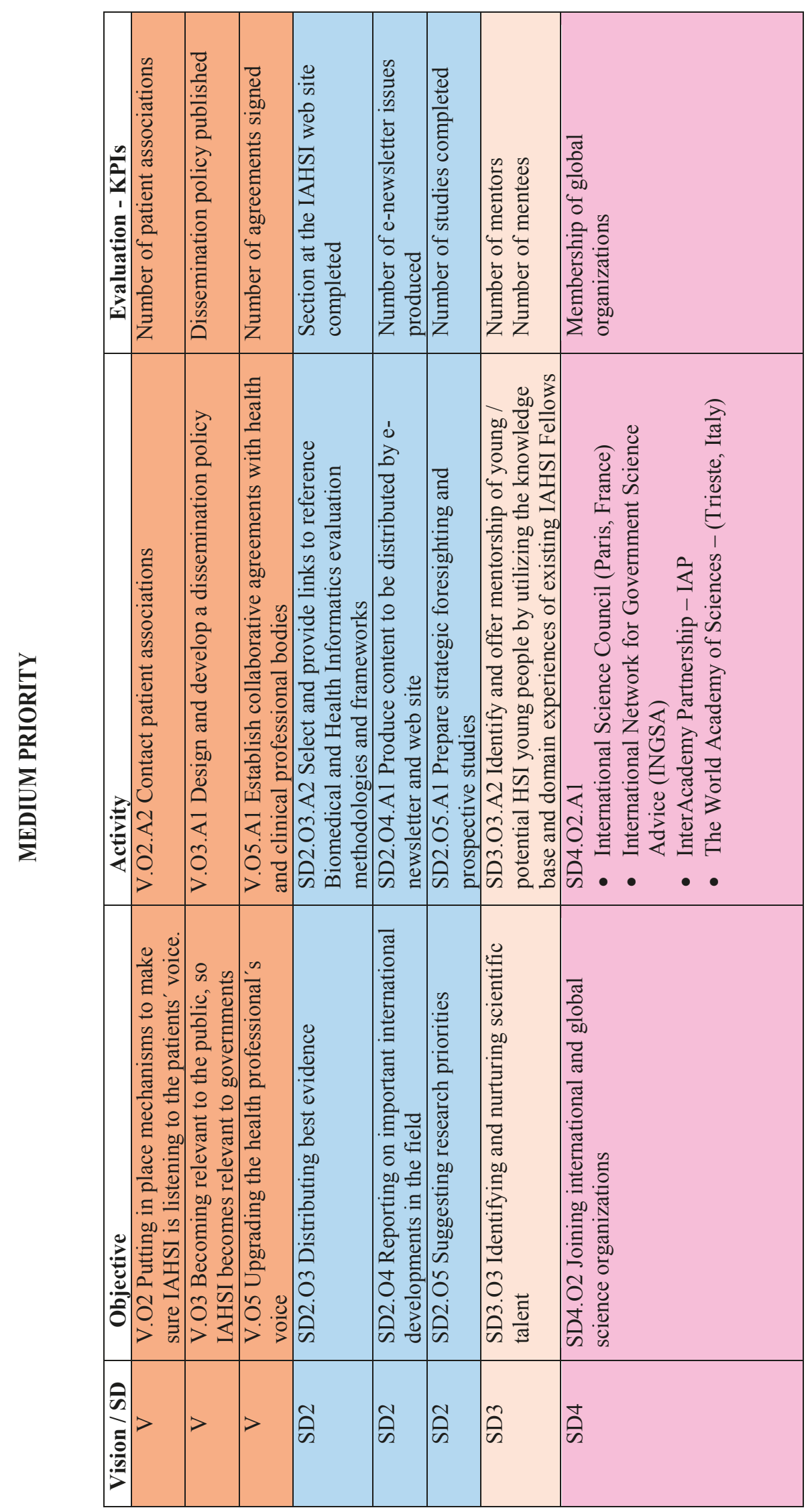

\section{Evaluation of Progress in Implementing the Strategy}

Besides the specific KPIs already included in the strategy to monitor the progress of the Academy in completing the different planned activities, the Academy needs to address how the impact of the Academy can be measured by relevant and acceptable metrics.

Some suggested KPIs include:

\section{Operational KPIs}

- Number of Fellows

- Number of countries with Fellows

- Level of activity

- Products released

- Web activity

- Internal communication platform activity

\section{Financial KPIs}

- Maintain net operating cash flow

- Secure grants / external funding

- Contribute to workforce capacity building and $R \& D$ activities with any surplus funds

\section{Global Health KPIs}

- Better health outcomes for individuals

- Advanced population health.

\section{Acknowledgements}

Academy Fellows providing feedback and input to this strategy and focus areas document were, in particular: Najeeb AlShorbaji (Jordan), Bernd Blobel (Germany), Christopher G. Chute (USA), Don E. Detmer (USA), Francis H. Roger France (Belgium), Sashi B. Gogia (India), Kathryn J. Hannah (Canada), Terry J. Hannan (Australia), William R. Hersh (USA), George Hripcsak (USA), Evelyn Hovenga (Australia), Betsy L. Humphreys (USA), Rada Hussein (Egypt), Isaac S. Kohane (USA), Teng Liaw (Australia), Nanci M. Lorenzi (USA), Alexa T. McCray (USA), Clem J. McDonald (USA), John Mantas (Greece), Heimar de Fátima Marin (Brazil), George I. Mihalas (Romania), Jochen R. Moehr (Canada), Anne Moen (Norway), Ramin Moghaddam (Iran), Lincoln de Assis Moura (Brazil), Jean Roberts (UK), Amnon Shvo (Israel), Edward H. Shortliffe (USA), Jan Talmon (The Netherlands), William M. Tierney (USA), and Lucy Westbrooke (New Zealand). 


\section{Bibliography}

- Haux R. Visions for IAHSI, the International Academy of Health Sciences Informatics. Yearb Med Inform 2018:7-9.

- Crist E. Reimagining the human. Science 2018;362(6420):1242-4.

- France FR. Need for Physician Empowerment in front of Artificial Intelligence overruling. Insights Biomed Res 2018;2(1):40-2.

- Advisory role of academies in the information-rich society -22-23 October 2018 in Tallinn https://www. ias.ac.in/About_IASc/Role_of_the_Academy/.

- Science advisory role of national science academies. S Afr J Sci 2016;112(7-8). Http://dx.doi. org/10.17159/sajs.2016/a0169.

- Gluckman P. Keynote address. Proceedings of the InterAcademy Partnership (IAP) Conference on Science Advice; 2016 February 28 - March 01; Hermanus, South Africa. Pretoria: ASSAf; 2016. p. 6-8.
- International Network for Government Science Advice, "Science Advice to Governments" (conference, Auckland, New Zealand, August 28-29, 2014), http://www.globalscienceadvice.org/ archive-2014-conference.

- Hassan M, ter Meulen V, McGrath PF, Fears R. Academies of Science as Key Instruments of Science Diplomacy; 2015. http://www.sciencediplomacy.org/perspective/2015/academies-science-key-instruments-science-diplomacy.

- The Role of National Academies in Science Advice to Governments. https://www.ingsa.org/ wp-content/uploads/2017/05/ROLE-of-ACADEMIES_Auckland-April-2017_final-report-1.pdf.

- Blair PD. The evolving role of the US National Academies of Sciences, Engineering and Medicine in providing science and technology policy advice to the US government. Palgrave Communications 2016;2:16030. https://www.nature.com/articles/ palcomms 201630 .

\section{Correspondence to:}

Prof. Dr. Reinhold Haux

President of IAHSI

Peter L. Reichertz Institute for Medical Informatics of TU Braunschweig and Hannover Medical School Muehlenpfordtstr. 23

D-38106 Braunschweig Germany

Tel: + 49(0)5313919500

Fax: + 49(0)531 3919502

E-mail: Reinhold.Haux@plri.de www.plri.de 